\title{
MANAGING MENTALLY ILL INMATES IN PRISONS
}

\author{
KENNETH ADAMS \\ JOSEPH FERRANDINO \\ University of Central Florida
}

\begin{abstract}
Mentally ill inmates now comprise a substantial portion of the prison population and pose administrative and therapeutic challenges to prison administrators and mental health professionals. Some evidence suggests that both the size of the population and the seriousness of their illnesses are increasing. Given this context, several issues are highlighted and discussed in terms of contemporary efforts to deal with mentally ill inmates. Specifically, discussion centers on the use of actuarial devices for prediction and classification, the conflict between treatment and control and the relation between treatment and management, the distinction between risks and stakes and use of the environment as therapy, use of medication and isolation, and the role of correction officers in mental health treatment. The authors make an argument for more sophisticated approaches in dealing with mentally ill inmates that rely on expanded therapeutic options, broader role definitions for prison staff, and an evidence-based approach for individualizing treatment.
\end{abstract}

Keywords: mentally ill inmates; treatment; management

$\mathrm{B}$ $y$ all objective measures, correctional facilities in the United States have become the primary mental health institutions in the nation (American Psychiatric Association, 2004; Fellner, 2006; Treatment Advocacy Center, 2007). As a result of the deinstitutionalization movement, state hospital populations went from 550,000 psychiatric patients in 1956 to 61,700 in 1996 , for a decline of nearly $90 \%$. These patients were released to the community, often without adequate support services, and many later found themselves caught up in the criminal justice system. Thus, it is unsurprising that presently the three largest psychiatric institutions in the country are the Los Angeles County Jail $(17,000)$, New York City Rikers Island $(13,500)$, and the Cook County Jail in Chicago $(9,000)$ (Parker, 2006).

A number of research studies have certified that a substantial number of mentally ill persons are housed throughout our state and federal prison systems. Although specific estimates vary depending on the research methodology and definition of mental illness used (Toch, 2007), the proportion of mentally ill prison inmates is generally estimated to be around 16\% (Ditton, 1999), based on mental health service records. The problem of mentally ill inmates in prison is serious and substantial, and indications are that the situation may be getting worse. Data from the Florida Department of Corrections (n.d.) highlight the potential urgency of the situation. The 2005-2006 annual report indicates that " $16.5 \%$ of Florida's inmates receive ongoing mental care" (p. 47). Inmates who receive care are classified into three categories of mental disorders: mild ( $\mathrm{S} 1$ and $\mathrm{S} 2)$, moderate (S3), and severe

\footnotetext{
AUTHORS' NOTE: Correspondence concerning this article should be addressed to Ken Adams, University of Central Florida, College of Health and Public Affairs, 3280 Progress Dr., Orlando, FL 32826-0544; e-mail: kenadams@mail.ucf.edu.
} 
(S4 to S6). Looking at the historical picture, we find that from 2002 to 2006, the number of "mild" inmates fluctuated but essentially remained unchanged over time. However, inmates classified as "moderate" increased by nearly one third, going from 8,053 to 10,553, whereas inmates classified as "severe" doubled, going from 402 to 812 . Clearly, Florida is admitting over time greater numbers of inmates with more serious mental illnesses. Given that Florida has the third largest prison system in the country, it may not serve as a bellwether for trends in other states. However, experiences in the Oklahoma prison system, where the number of inmates on psychotropic medication tripled from 1998 to 2005, would seem to corroborate Florida's experience (Fields, 2006).

In terms of specific illnesses, prison inmates tend to have the same disorders as the general population, albeit with greater frequency and intensity. According to the American Psychiatric Association (2004), the most common mental illnesses in the inmate population are depression, schizophrenia, and bipolar disorder, a finding that applies to prisons in both the United States and the United Kingdom (Gordon, 2002). Inmates are also more frequently diagnosed with personality disorders, a situation that is confounded by antisocial personality disorder, which has as its primary diagnostic criteria antisocial or criminal behavior, so it is a diagnosis for which most inmates qualify. Finally, inmates are more likely to have co-occurring substance abuse disorder. For example, one study found that about $45 \%$ of mentally ill jail inmates showed comorbidity of a major mental illness and a substance abuse disorder (Young, 2003). Co-occurring disorders are more difficult to treat because the illnesses can interact with each other and because treatment strategies for the individual disorders may be at odds with each other.

In many respects, we already know much about the contours of the inmate mental health problem, and we also know that solutions are complex and gaining in urgency. More inmates with mental illness and more inmates with serious mental illness are entering our prison systems, and there is little reason to believe that this trend will reverse. Given that a significant expansion of resources for state psychiatric care systems is highly unlikely, prison administrators have come to recognize that they need to develop programs, techniques, and strategies to effectively manage this population. A recent report acknowledged as much by noting that "finding safe, humane, and non-punitive methods for handling inmates who are experiencing the symptoms of mental illness is an ongoing challenge for prison administrators" (Oregon Department of Corrections, 2004, p. 45). Despite the high prevalence of mentally ill inmates, the U.S. Bureau of Justice reported that in 2000 only $51 \%$ of state prisons provided 24-hour mental care (Beck \& Maruschak, 2001). Thus, correctional management is playing catch up with this problem. This article discusses some of the major issues that need to be addressed as attempts are made to improve inmate mental health care.

\section{INTAKE, SCREENING, AND ASSESSMENT}

Prisons have opportunities at a variety of junctures to identify mentally ill inmates, and perhaps the most widely used juncture is intake. According to a Bureau of Justice Statistics report, about $70 \%$ of state prisons screened inmates for psychiatric illnesses at intake in 2000 (Beck \& Maruschak, 2001). A variety of screening instruments and practices have evolved over time, ranging from clinical interviews and evaluations to actuarial or statistical approaches that minimize human judgments. At this juncture, the purpose of assessment 
is to identify mental health problems or potential mental health problems and evaluate their need for treatment. Another goal is to identify inmates who are likely to be a danger to themselves or others. With regard to screening and assessment practices, there have been several notable developments.

During the past few decades, there has been continuing debate over the relative utility and accuracy of clinical versus actuarial prediction models, especially in the context of predicting dangerousness or criminal recidivism. For the most part, the debate has been resolved in favor of statistically based actuarial models for predicting who is likely to be violent or to reoffend. Monahan (1996) argued that because actuarial models are more accurate at predicting future behavior, they should be seen as a replacement for clinical approaches, rather than as a supplement. He also noted that courts have found the clinical approach too unreliable, and thus, the catalyst for removing clinical elements from predictions is the justice system itself. In a recent development, Banks and colleagues (2004) utilized a multitest approach to actuarial risk, rating offenders on several instruments. Their focus was on consistently identifying offenders rated as "high" or "low" risk across multiple tests in a type of convergent validity strategy. Arguably, this strategy draws from the strengths of various instruments and comes closer to allowing individuals, rather than groups, to be assessed more precisely in terms of their probability of risk. The unique contribution of this research is not in determining which test is best or most accurate but in combining several tests in ways that allow for narrower or tighter specification of group at risk. Perhaps we will see more such efforts at combining risk assessment instruments.

Taxman, Cropsey, Young, and Wexler (2007) summarized current uses of risk assessment models by correctional facilities to assess substance abuse treatment needs and recidivism. They found that in making treatment placement decisions, a majority $(58.2 \%)$ of institutions used a standardized substance abuse screening tool, and a minority $(34.2 \%)$ used an actuarial risk tool for gauging risk. They argued that use of these tools needs to be expanded if high-intensity treatment programs, which often involve high-risk individuals, are to increase and if treatment effectiveness is to be enhanced through better matching of individual treatment needs and available service. In the end, the authors discussed a fourthgeneration assessment model that incorporates severity of need through the use of standardized metrics rather than clinical evaluation.

The trend for actuarial prediction for juvenile offenders is developing in slightly different ways. Edens and Campbell (2007) reported that the "construct of psychopathy is assuming what appears to be an ever-increasing role in clinical and legal decision making toward youth involved in the juvenile or criminal justice system" (p. 1). In this context, the prediction instrument most commonly used is the Hare Psychopathy Checklist-Youth Version. Edens and Campbell conducted a meta-analysis of research on the predictive ability of Hare's Checklist for juvenile institutional conduct. They concluded that perceptions in the field of the instrument's predictive utility are inflated, and they argued for more research on predictive assessments in relation to treatment outcomes.

The utility of psychopathy as a clinical concept has been debated for some time. Recently, Walters, Duncan, and Perez (2007) used the Psychopathy Checklist-Revised on a group of 409 male federal prison inmates across a variety of security levels. On the basis of their analyses, they concluded that the concept of psychopathy is best viewed as a continuum and that even large differences in scores reflect variation in degree (quantitative differences) rather than variation in kind (qualitative differences). In a similar fashion, Vien 
and Beech (2006) noted that "the link between psychopathy and offending seems to lie within the levels of risk of recidivism for violent sexual and violent nonsexual reoffending and the personality characteristics of psychopathy" (p. 166). Thus, both groups of authors argued that a categorical approach does not fully capture all the dimensions of psychopathy that are related to risk. This point is especially germane to Eden's and Campbell's (2007) argument that we need more research on treatment outcomes because prediction instruments can define who gets treated, and the information used in the prediction instrument will in some way shape how we think about the problem.

From some perspectives, the increasing use of "psychopathy" in classification and prediction decisions is disturbing. There is considerable overlap between antisocial personality disorder and psychopathy. Many inmates who qualify for one label also qualify for the other. If one looks at the criteria for antisocial personality disorder, which are mostly behavioral, the picture is one of a typically serious delinquent who has moved on to adult crime. The label also carries a moral judgment in that "individuals who are described with this designation are presumptively sleazy, unsavory, repugnant and dangerous" (Toch, 1998, p. 151) and therefore less deserving of treatment services. Also, there is general consensus that effective treatment for psychopathy or for antisocial personality disorder is either nonexistent or very impractical in terms of time, cost, and effort. Thus, there is the real possibility that these labels are used to designate uninviting mental health clients as the responsibility of some other actor in the criminal justice system, on the grounds of being either unfit for treatment or untreatable (Agee, 1979; Toch, 1998). Thus, the increasing salience of antisocial personality disorder or psychopathy, especially among serious youthful offenders, in classification, treatment, and risk-prediction decisions may lead to situations in which their pathology is de-emphasized and replaced with character assessments (Toch, 1998).

Finally, in the transition from the clinical to the actuarial approach, a note of caution was offered by Clark, Fisher, and McDougall (1993) in terms of using preconviction data to determine postrelease risk owing to the time that it takes to process people into prison. To counteract this problem, assessment is essential, not just at intake but also as an ongoing process while the inmate is incarcerated. In particular, it is important to take into account the prison environment in which the inmate lives and the resources of the prison system as they relate to the handling and treatment of mentally ill inmates. In a later section, we return to the issue of prison environments, and now we take up the issue of treatment and inmate control.

\section{TREATMENT AND CONTROL}

The relationship between treatment and control, and striking an appropriate balance between the two objectives, is a critical management issue. As Byrne and Roberts (2007) pointed out, "There is no 'one-stop shopping' offender typology available that can identify the risk level, targeted treatment protocols and control levels" (p. 490). Until such typologies are developed, if indeed they can be, professional judgments and evaluations by clinicians and prison administrators that balance concerns of treatment effectiveness and risk will play a crucial role in developing treatment strategies for mentally ill inmates. In making these judgments and evaluations, clinicians are likely to emphasize diagnosticrelated information, whereas prison administrators are likely to center on information relevant to the safe management of the correctional institution. 
The treatment-custody conflict was recognized early on by Clemmer (1940), and since that time it has become clear that there is no simple and easy resolution for the conflict. More recently, Fellner (2006) characterized the problems of dealing with mentally ill offenders in a correctional setting as

an inherent tension between the security mission of prisons and mental health considerations. The formal and informal rules and codes of conduct in prison reflect staff concerns about security, safety, power, and control. Coordinating the needs of the mentally ill with those rules and goals is nearly impossible. (p. 391)

One can add that very often there is a serious disjuncture between the treatment needs of the offenders and the resources available for treatment, and this resource gap has a substantial effect on administrative handling of mentally ill inmates (Clements et al., 2007).

Faiver (1998) described the delicate balancing act required by administrators to maintain order while trying not to punish inmates for behavior that is beyond their control because of mental illness, especially when some inmates are not able to clearly understand the rules or even comprehend that the rules have been broken. In the inmate vignettes provided in Lovell's article in this volume, it is not difficult to see how anxiety, depression, paranoia, delusions, hallucinations, and other types of psychopathology interfere with an inmate's ability to follow institutional rules. There are many intertwined issues regarding the treatment of mentally ill inmates in the prison community, and chief among them is victimization. As the Treatment Advocacy Center (2007) pointed out,

Illogical thinking, delusions, auditory hallucinations, and severe mood swings often lead to bizarre behavior by individuals with severe brain disorders who are in jails and prisons. Such bizarre behavior is disquieting to other non-ill inmates who frequently react with violence against those with brain disorders, thereby making life in jail a brutal experience for them. A serious form of assault that sometimes occurs behind bars is attempted or actual rape. All inmates in jails or prisons are at risk for such attacks, but inmates who are confused by their illness and less able to defend themselves are more vulnerable. (p. 4)

It remains to be seen whether the Prison Rape Elimination Act of 2003 will bring specific benefits to mentally ill offenders (U.S. Bureau of Justice Statistics, 2004). In addition, the mentally ill not only are potential victims in the prison setting but also need to be considered as potential aggressors. It has long been established that inmates with mental illness are more inclined to commit infractions in the prison setting, including assaults and other forms of violence (Toch \& Adams, 1986).

Another factor to be considered is that inmates with mental illness also are more likely to reoffend than are other inmates (Heikes, 2000). According to Ditton (1999), prison inmates identified as mentally ill also were more likely to serve longer sentences than were other inmates, with the average being 12 additional months. Fields (2006) found that in Oklahoma inmates with mental illness were less likely to be paroled than those without identified mental illness. Thus, under the current situation, inmates may have diminished motivation to seek help because such assistance may be implicated in longer prison sentences.

Overall, we have considerable information on the problems that mentally ill inmates present in prisons, and we also have a good understanding of the scope of these problems. The lack of resources directed at these issues, however, which often show up in a scarcity of programmatic options, can put a variety of institutional actors in difficult situations. Next, we examine some of the related management issues and options. 


\section{RISKS AND STAKES}

A significant aspect of treatment strategies for mental disorders is trial and error. Clinicians use their experience to predict likely reactions to various treatments or interventions and then use their judgment to identify what would seem to be the best course of action. However, events do not always turn out as predicted, and so clinicians constantly modify their approaches with individual patients based on feedback as to what works best. In the context of correctional institutions, the trial-and-error aspect of mental health treatment has to be taken very seriously because some adverse outcomes, such as those involving violence, may be very harmful. Quite naturally, a conservative posture of risk avoidance and of adopting low-risk strategies is preferred.

As Gottfredson and Gottfredson (1988) noted, we tend to overlook the distinction between risk, which is the probability of a given event happening, and stakes, which is an assessment of the seriousness or gravity of that event should it happen. In the criminal justice system, we are often concerned with "high-risk" individuals and "high-stakes" decisions. In treating mentally ill inmates, the risks and stakes of treatment decisions can vary, and they can do so quite independently of each other. We should not let our concern with high-end extremes tempt us into becoming unmindful of this fact. Furthermore, treatment options may affect risk or stakes, or perhaps both, and a change in either dimension can substantially influence our assessment of a situation.

The distinction between risk and stakes is important because sometimes decisions that are high on one dimension, such as risk, can be made acceptable by minimizing the other dimension, such as stakes. Thus, for example, an inmate with a high probability of breaking the prison rules does not have to be punished in the name of general deterrence if the inmate is in an environment, say a special treatment program, where rules violations pose a lesser threat to prison order. Conversely, high-stakes decisions, such as how to respond to an inmate who threatens self-injury, can gain some flexibility if the risk of harm can be minimized, say by constant interaction and communication with staff. Prediction devices that usually look to make categorical assessments that identify high-risk individuals are not very useful for these kinds of treatment decisions because the range of factors being considered typically is limited.

Clinical decisions involving mentally ill inmates often involve evaluating several types of stakes or adverse consequences. First, there is the possibility that the inmate's psychological condition may deteriorate, thereby worsening his or her mental health. There is also the possibility that the inmate will be physically harmed, either directly through selfinflicted injury or indirectly through provocation of other inmates and staff. Finally, there is the possibility that other actors, such as prison staff or other inmates or civilians in the case of release to the community, will be harmed. Actuarial instruments are not so advanced, and these distinctions in types of harm are not easily separated; nor do these instruments have sufficient theoretical grounding or dynamic capacity to accommodate changing situations and environments that would produce more refined predictions.

Gottfredson and Gottfredson (1988) suggested that criminal justice officials develop a matrix in which risks and stakes are juxtaposed to structure decision making in ways that lead to reduced levels of social harm. Picking up on this notion, clinicians could think in similar terms, at least more explicitly so, and then consider how each action within the range of available treatment strategies can affect the risks or stakes. This line of thinking may help to create more options for high-risk inmates or high-stakes situations. The situation described 
in Elaine Lord's article in this volume regarding the inmate Miriam who was moved through various treatment environments as circumstances warranted is an example of this type of thinking. Also, if related clinical assessments, treatment experiences, and positive and negative outcomes are recorded in a systematic way, considerable strides could be made in terms of developing evidence-based treatment strategies for mentally ill inmates.

\section{RISK MANAGEMENT AND TREATMENT}

Byrne and Roberts (2007) identified mentally ill inmates as one of several special "classifications" of offenders who require a different approach if we are to effectively address the problems of these inmates. More specifically, Byrne and Roberts argued that we should not think in terms of mutually exclusive strategies of either changing the offender or controlling the offender. Rather, they contended that we can significantly reduce the chances of mentally ill inmates reoffending if proper treatment is provided. From this perspective, treatment can be seen as a form of risk management that furthers public safety goals. The integration of treatment and risk management would start at intake to the facility and continue throughout the treatment program. Although Byrne and Roberts described this approach as a paradigm shift in relation to the handling of violent mentally ill offenders, their point can be applied more generally to mentally ill inmates.

This thinking is consistent with findings from Ax and colleagues (2007) and their position that a multidimensional rather than categorical approach to treatment would be more beneficial. A major issue is that when inmates are categorized, treatment tends to be fragmented by treating one problem at a time. Ax et al. noted that a multidimensional approach, which would address several problems at once, would be beneficial in terms of more individualized and holistic treatment.

\section{ENVIRONMENTS AS THERAPY}

Not all prisons environments are the same. Some prisons seem quiet and reserved, others seem noisy and active, whereas others seem safe and predictable. Within prisons, environments also vary from cell block to cell block or from one program or work setting to another. Across these environmental variations, inmates can find niches or specialized environments in prison in which they function better (Toch, 1992). From a therapeutic perspective, it is possible to take advantage of these specialized environments to reduce stress or other detrimental experiences. For example, Ax et al. (2007) noted that there are distinct environmental triggers for irritable aggression. This type of aggression often occurs in response to a frustration or insult. It is accompanied by angry emotions, it is not directed at a tangible goal, and the outburst usually is disproportionate to the triggering stimuli. With more careful matching of inmates, especially those who are mentally ill, to prison environments, it is likely that the incidence of such violence can be reduced.

In many instances, mentally ill inmates need to be insulated from certain aspects of prison environments. Carr and colleagues (2006) noted that strategies of adaptation that integrate inmates into the prison culture can be counterproductive to therapeutic goals for mentally ill inmates. For example, mentally ill inmates often have greater difficulties 
socializing with inmates, and this deficit can have harmful consequences, including victimization and acting out behavior. Therefore, they may benefit from less socialization or more structured socialization. Some programs seek to incorporate specialized environments into treatment strategies by combining environmental features with other therapeutic modalities. An example is the McNeil Program, which was established for mentally ill offenders at the McNeil Island Corrections Center in Washington State, with three coordinated program settings that emphasized return to the general population. This program also had three main treatment strategies: "careful monitoring and counseling concerning medications by psychiatrists and nurses; psychoeducational classes (anger management, chemical dependency) and a low-stress milieu" (Lovell, Johnson, Jemelka, Harris, \& Allen, 2001 , p. 475). Follow-up research indicated that the incidence of psychiatric symptoms was reduced while inmates were in the program, and the environmental features rated most positive by the inmates were "architecture, freedom of movement, protection from the stresses of general population and availability of activities" (Lovell et al., 2001, p. 484).

The therapeutic community (TC) places the milieu concept squarely at the center of the treatment process. The core element of TC is "the community as method" (Saum et al., 2007, p. 1169). These therapeutic milieus have largely been developed in terms of programs that deal with substance abuse (Linhorst, Knight, Johnston, \& Trickey, 2001; Peat \& Winfree, 1992; Smiley-McDonald \& Leukefeld, 2005; Taxman \& Bouffard, 2002). However, modifications of the approach have been made for other offender populations in need of treatment, such as the mentally ill (Saum et al., 2007). These modifications are made possible because one of the basic pillars of the TC approach is to develop and improve the prosocial skills of program residents.

Research on TCs in correctional facilities has found that the TC environment was better than that of the general population, meaning there were demonstrably lower levels of disorder and that inmate perceptions of the environment were more positive (Dietz, O'Connell, \& Scarpitti, 2003). Peat and Winfree (1992) warned that the biggest threat to the TC model is the prison subculture and prisonization, aspects of prison life that are often noted to work to the disadvantage of mentally ill inmates. The same research also gave TCs credit for easier facility management because of positive treatment outcomes and improved relationships between inmate and staff.

One study found that an important factor in reducing recidivism and relapse in TC clients, in this case substance abusers and sex offenders, was provision of community aftercare once the inmate was released (Wormith et al., 2007). Although institutional treatment can successfully operate in the prison environment, aftercare on the outside becomes a critical factor in determining whether inmates will be successful on release from the program. We know that mental health programs and interventions exist that achieve positive results, but the rest of the system needs to do its part when the inmate is released if we are to minimize the recidivism of mentally ill inmates.

\section{SEGREGATION AND ISOLATION}

Secure housing unit is another term for isolation cells in a correctional facility, which may be used on a short-term emergency basis or as a longer-term residential assignment. The practice of segregating or isolating inmates is done for several reasons. First, segregation protects staff and other inmates from harmful behaviors, such as assault, and removing the 
inmate to a special setting helps to prevent situations from escalating, thereby maintaining order in the general prison population. Second, segregation protects the inmate from being victimized, and it also can help to protect an inmate who is intending self-harm. However, as Fred Cohen's essay in this volume points out, the practice can have negative consequences, especially for mentally ill inmates.

A lengthy report by Human Rights Watch (2003) argued that segregation increases the risk of suicide for all inmates, but more so for the mentally ill. Carothers (2003) offered an explanation for this increased risk based on experiences in Maine's correctional facilities, including the "strip down and isolation" of mentally ill inmates. Specifically, she argued that potentially suicidal inmates saw this process as punishment, and to avoid this experience they kept their thoughts to themselves, including suicidal ideation, which increased their chances of suicide because they feared seeking out help.

In a New York Times article, Zielbauer (2003) reported that one in four New York State prison inmates who are in punitive segregation are mentally ill, a fact confirmed by the Correctional Association of New York, a nonprofit organization that is critical of state prison policies toward the mentally ill. Fellner (2006) observed that there can be a fine line between treatment and punishment with regard to isolation, and she noted that "punishment is particularly counter-productive-indeed dangerous to the prisoner-when it consists of placing mentally ill prisoners in prolonged segregation" (p. 401). This practice is particularly troubling given that mentally ill inmates are overrepresented in segregation units, often because of their inability to comport with institutional rules. The practice of isolation can be seen as even more insidious when one realizes that punitive segregation is one of the cheaper options for dealing with mentally ill inmates.

Clements and colleagues (2007) emphasized that the research on the effects of segregation is inconclusive, partly owing to the complexity of the situation given that "prison segregation has too many faces" (p. 925). Based on prior research, they argued for a more complex analysis of segregation that examines features of the person (e.g., behavior and motivation), the environmental context (e.g., availability of programming and services), and process (e.g., quality of offender interactions with staff and other inmates) (p. 926). In the end, they called for better and more comprehensive assessments of the impact of various correctional settings. We would add that such assessments should be done in the context of examining their impact on the stakes and risks of various therapeutic actions for various types of offenders.

Smith (2006) reached a conclusion similar to that of Clements and colleagues (2007) with regard to substantial variation in the impact of segregation on inmates. Specifically, Smith pointed to the duration and characteristics of confinement and individual qualities of the inmate. However, Smith argued that, notwithstanding this variability, the evidence indicates that solitary confinement is a harmful practice in that it "causes serious health problems for a significant number of inmates" (p. 503), and the deleterious effects of isolation can be even more pronounced for inmates with mental illness.

\section{MEDICATION}

Treating mentally ill inmates with psychotropic drugs, or pharmacotherapy, is very common. The U.S. Bureau of Justice Statistics reported that, in 2000, $73 \%$ of state prisons in the United States distributed psychotropic drugs to the inmates housed in their facilities, 
with an estimated 114,400 inmates nationwide receiving psychotropic drugs while incarcerated (Beck \& Maruschak, 2001). For practical reasons, drugs often are the treatment modality of first choice because, as Parker (2006) noted, "mental health interventions in the correctional setting are generally limited to psychiatric medications due to limits on space, time and/or money" (p. 37), a view also shared by Thorburn (1995).

In a Frontline documentary on mental illness among inmates, it was noted that about two thirds of the inmates in state facilities who received counseling or psychotropic medications were in facilities that did not specialize in providing mental health services in confinement (Public Broadcasting Service, n.d.). Given this context, one can question whether the pharmacotherapy is being properly administered. One can also question whether the pharmaceuticals are being primarily used to control behavior.

A study by Baillargeon, Black, Contreras, Grady, and Pulvino (2002), which looked at prescribing patterns for antidepressant medications among inmates with depressive disorders in the Texas prison system, highlighted some of the complexity of the medication issue. The researchers found that the prescription patterns varied in terms of types of medication initially prescribed and the sociodemographic characteristics of the inmate. Some of the findings were consistent with prescribing patterns in the community (i.e., for female clients), whereas other prescribing patterns were opposite those found in the community (i.e., for initial medication and for Hispanic clients). Clearly, more research needs to be done on use of psychotropic medications in prisons before definitive conclusions can be reached.

Although clinicians may have fallen out of favor in the area of assessment and prediction, they certainly are important for prescribing medications. Ax and colleagues (2007) argued that there is a link between certain types of mental illness and biological conditions, such as too much testosterone or a lack of serotonin leading to aggression. Actuarial assessments may find it difficult to capture such links. Clinicians also have responsibility for adjusting medications as needed to control symptoms, thus operating more in terms of a dimensional approach rather than the categorical approach favored by actuarial instruments. As medications are adjusted, clinicians assess inmates over time, both medically and in terms of prison performance, to determine how the inmate's condition is changing in response to treatment. There is a move underway to give psychologists limited authority to prescribe certain medications (Rabasca, 1999). It is not clear if the move to give limited prescription authority to psychologists will be successful. However, the change may be beneficial in the long run to mentally ill prison inmates if any problems created by limited access to physicians are alleviated. Also, if psychologists are detailed and conscientious about their clinical notes, and if methods for systematic review are applied to this information, it may be possible to develop evidence-based best practices for the treatment of mentally ill inmates.

\section{CORRECTIONAL OFFICER INVOLVEMENT}

Among the various management issues relating to mentally ill inmates, there has been significant discussion about the role that prison employees, especially correctional staff, should play in that process. Most often, the discussion occurs in the context of conflicting goals between treatment and custody and how this conflict is a curse or strain for correctional officers. Sometimes, however, the discussion is in the context of specially trained 
corrections officers who would participate as members of multidisciplinary treatment teams that specialize in mentally ill inmates.

Dvoskin and Spiers (2004) developed a more elaborate, four-part, multidisciplinary approach to delineate the activities of corrections officers with regard to inmate mental health treatment, incorporating the aspects previously discussed above. According to these authors, corrections officers can participate in inmate mental health treatment in the following ways:

Counseling and psychotherapy—talking with inmates

Consultation-talking about inmates

Special housing, activities, and behavioral programs

Medication

For Dvoskin and Spiers (2004), this typology is not simply descriptive in the sense that it identifies the range of possible types of involvement. Rather, they argued that correctional staff should be prepared to perform each of these activities, with the dual benefits of improving the quality of mental health services provided and reducing stress on the staff and inmates. For some, however, this may seem to be a lofty goal, given that, as Bonner and Vandecreek (2006) pointed out, mental health workers in prison settings face ethical quandaries because of the need to balance "the mental health of offenders with the control, security and paramilitary structure of the prison system" (p. 542).

The view of correctional officers as having a participatory role in the mental health treatment of inmates is an emerging paradigm that makes a lot of sense. As Appelbaum, Hickey, and Packer (2001) noted, the correctional line officer interacts with inmates and observes their behaviors 24 hours a day, making officers the first to observe conduct and demeanor that may connote mental illness. Thus, a critical role that correctional officers can play in a multidisciplinary treatment approach is timely identification of inmate problems, which facilitates more effective intervention. Appelbaum and colleagues conceded that the current paradigm is one in which many correctional staff tend to view inmates strictly as security threats. Thus, it is only through training and developing a shared value system between security and mental health staff based on the common ground of enhancing the operations of the institution and improving the functioning of the inmates that corrections officers can be brought in as full partners in a multidisciplinary treatment approach.

Despite the promise that the correction officer as mental health agent paradigm holds, Fellner (2006) noted that

most prison systems do not provide correctional officers with more than minimal mental health training. Officers typically do not understand the nature of mental illness and its behavioral impact. They cannot distinguish - and may not even know a distinction exists - between a frustrated or disgruntled inmate who "acts out" and one whose "acting out" reflects mental illness. They assume misconduct is volitional or manipulative. (p. 396)

Nonetheless, relatively small investments in training can yield substantial returns. Parker (2006) reported that the National Alliance of Mentally Ill in Indiana developed, in conjunction with Indiana University, a 10-hour curriculum for correctional officers to teach them about mental illnesses. Subsequent to implementation of the program in the Secure Housing Unit of Wabash Valley Prison, incidents of use of force by officers and battery with bodily fluids by inmates both decreased. 
Fellner (2006) quoted concerns expressed by several prison administrators that in giving a corrections officer quasi-mental health responsibilities, the officer would respond differently to mentally ill inmates, such that other inmates might feign mental illness to gain an advantage, such as avoiding punishment for their actions. Further complicating the situation is the view, as reflected by Jeglic, Vanderhoff, and Donovick (2005), that many inmates use self-injurious behavior to manipulate their housing assignment or to get attention from the correctional staff. Narrowly circumscribed views of mental illness, peppered with cynical assessments of inmate motivation, will limit the practical contribution that correctional officers can make in the handling of inmates with mental health problems. These issues are part of a larger set of ethical concerns when professionals have multiple roles with potentially conflicting role responsibilities. Both the American Correctional Health Services Association and the American Association for Correctional and Forensic Psychology have developed ethical codes that serve as guides for decision making. Although some experts differ in their interpretations of these codes, there appears to be a consensus, especially from "insiders" working in corrections, that the codes offer a "well-balanced, practical approach" that well could serve as a basis for correction officer training in this area (Bonner \& Vandecreek, 2006, p. 562).

\section{CONCLUSION}

A substantial proportion of the inmate population is in need of mental health treatment, and these inmates present serious challenges as staff try to juggle treatment concerns with correctional administration concerns. There is some indication that the problem of mentally ill inmates is increasing, as more inmates with more serious mental health issues appear to be entering prison systems. These increases are occurring in the context of already strained and inadequate resources, and there are a limited number of new initiatives to address the predicament. Given this context, some of the key issues pertaining to the management of mentally ill inmates were reviewed in this essay.

It was noted that actuarial prediction devices are being used more frequently for a variety of treatment and security decisions, including intake, assessment, classification, and program assignment. These instruments often focus on offenders at the extremes, such as "high risk" offenders, and so their utility across a wide range of inmates is not as well developed. Furthermore, a focus on extremes often leads to categorical type assessment, indicating that the inmate is of this type and not of that type. Although categorical assessments can facilitate decision making, research is beginning to indicate that inmate mental health problems are more productively viewed as dimensional rather than categorical. That is, inmate mental health issues vary more in terms of severity than type. Furthermore, research has indicated that many inmate mental health problems that are multidimensional such as combined substance abuse and psychiatric disorders also vary more in terms of quantity. Therefore, multidimensional classification devices are needed to address the situation.

It was also noted that many actuarial devices are not theoretically informed, and so they do not tell us much about the nature of the inmate problem. In addition, most of these devices are not tied to treatment strategies that are later assessed in terms of treatment outcomes. Therefore, from a clinical point of view, the devices do not tell us much about what 
to do with the inmate. Finally, mental health problems are not static, in that they change over time. Thus, actuarial evaluations need to be part of an ongoing assessment process, provided that the devices contain prediction items that capture important changes.

We also noted that correctional and mental health staff often report conflicts between treatment and control goals, and these goals tend to be viewed as mutually exclusive in a significant number of situation, in part because staff are often primarily trained to pursue security goals. Given that concerns for order and safety rank high in correctional settings, both mental health and correctional staff tend to become risk aversive in their decisions. We noted that one way to ameliorate this problem is to see treatment and behavior management as compatible rather than as conflicting, such that one works in service of the other. Appropriate and effective treatment serves a behavior management function that can enhance the overall operation of the institution. Likewise, effective behavior management can facilitate treatment. We also noted that risks, or the probability of something happening, can be distinguished from stakes, or the seriousness of the situation when that something happens. We may find more flexibility in treatment options when we realize that by changing the stakes, higher levels of risks can become acceptable, and one way to alter stakes is to configure environments such that risky behavior has less serious consequences.

We also discussed some of the treatment strategies that need more attention and development. For example, environmental components of treatment, as reflected in our experiences with TCs, are known to be important, and yet, we have not taken full advantage of this aspect of treatment. We also know that for mentally ill inmates assimilation into the prison culture can be harmful, and we may need to shelter them from these experiences. Thus, we need to create more "special" milieus so that inmates can locate settings that let them effectively function or, better yet, let them thrive.

We briefly mentioned the use of medication, which is the mainstay of treatment for mentally ill inmates and is likely to remain that way into the future. We do not know much about prescription practices for psychotropic medications in prisons, and we might add that medication refusal by inmates is a serious problem. Also, we mentioned the use of isolation cells, indicating that some argue they bring increased risk for self-injury, especially for mentally ill inmates, with others pointing out that there are various aspects to the isolation experience, such as the immediate environment, the offenders' characteristics and motivations, and the experiences while in isolation, that need to be studied before one can address issues of their appropriateness as a behavior management strategy.

Finally, we discussed the potential role of correction officers as quasi-mental health agents. Given the amount of time that corrections officers and inmates are in contact with each other, the idea makes good sense. In general, mental health training for corrections officers tends to be infrequent, and research has suggested that small amounts of training have potential to bring considerable rewards in terms of improved facility management. There also has been considerable discussion about expanding the role of some correctional officers to more fully embrace mental health treatment responsibilities. Very often, the discussion gets mired in debates over treatment custody conflicts and other ethical dilemmas. These issues are not insurmountable, and there are ethical codes that can be used as the basis for training. What is needed is a firmer commitment to change the paradigm of corrections officers as predominately security-oriented personnel by means of training and allocation of other resources. When this reorientation takes place, the management of mentally ill offenders in correctional settings will take a major leap forward. 


\section{REFERENCES}

Agee, V. (1979). Treatment of the violent incorrigible adolescent. Lexington, MA: D. C. Heath.

American Psychiatric Association. (2004). Mental illness and the criminal justice system: Redirecting resources toward treatment, not containment. Arlington, VA: Author.

Appelbaum, K. A., Hickey, J. M., \& Packer, P. (2001). The role of correctional officers in multi-disciplinary mental health care in prisons. Psychiatric Services, 52, 1343-1347.

Ax, R. K., Fagan, T. J., Magaletta, P. R., Morgan, R. D., Nussbaum, D., \& White, T. W. (2007). Innovations in correctional assessment and treatment. Criminal Justice and Behavior, 34, 893-905.

Baillargeon, J., Black, S. A., Contreras, S., Grady, J., \& Pulvino, J. (2002, April). Anti-depressant describing patterns among prison inmates with depressive disorders (Document 194054, Award 98-CE-VX-0022). Washington, DC: U.S. Department of Justice

Banks, S., Robbins, P. C., Silver, E., Vesselinov, R., Steadman, H. J., Monahan, J., et al. (2004). A multiple-models approach to violent risk assessment among people with mental disorders. Criminal Justice and Behavior, 31, 324-340.

Beck, A. J., \& Maruschak, L. M. (2001). Mental health treatment in state prisons, 2000. Bureau of Justice Statistics special report. Washington, DC: Government Printing Office.

Bonner, R., \& Vandecreek, L. D. (2006). Ethical decision making for correctional mental health providers. Criminal Justice and Behavior, 33, 542-564.

Byrne, J. M., \& Roberts, A. R. (2007). New directions in offender typology design, development, and implementation: Can we balance risk, treatment and control? Aggression and Violent Behavior, 12, 483-492.

Carothers, C. (2003, October). Overview of mental health issues in state prisons and county jails. Presentation to Commission to Improve the Sentencing, Supervision, Management, and Incarceration of Prisoners. Retrieved December 1, 2007, from http://www.maine.gov/spo/sp/commission/docs/Overview\%20of\%20Mental\%20Health\%20Issues\%20in\%20state\%20prisons.ppt.

Carr, A. W., Rotter, M., Steinbacher, M., Green, D., Dole, T., Garcia-Mansilla, A., et al. (2006). Structured assessment of correctional adaptation (SACA), a measure of the impact of incarceration of the mentally ill in a therapeutic setting. International Journal of Offender Therapy and Comparative Criminology, 50, 570-581.

Clark, D. A., Fisher, M. J., \& McDougall, C. (1993). A new methodology for assessing the level of risk in incarcerated offenders. British Journal of Criminology, 33(3), 436-448.

Clements, C. B., Althouse, R., Ax, R. K., Magaletta P. R., Fagan, T. J., \& Wormith, J. (2007). Systemic issues and correctional outcomes: Expanding the scope of correctional psychology. Criminal Justice and Behavior, 34, 919-932.

Clemmer, D. (1940). The prison community. Boston: Christopher.

Dietz, E. F., O'Connell, D. J., \& Scarpitti, F. R. (2003). Therapeutic communities and prison management: An examination of the effects of operating an in-person therapeutic community on levels of institutional disorder. International Journal of Offender Therapy \& Comparative Criminology, 47, 210-223.

Ditton, P. M. (1999). Special report: Mental health and treatment of inmates and probationers. Washington, DC: U.S. Department of Justice, Bureau of Justice Statistics. Retrieved April 9, 2008, from http://www.ojp.usdoj.gov/bjs/ pub/pdf/mhtip.pdf

Dvoskin, J. A., \& Spiers, E. M. (2004). On the role of correctional officers in prison mental health. Psychiatric Quarterly, 75(1), 41-59.

Edens, J. F., \& Campbell, J. S. (2007). Identifying youths at risk for institutional misconduct: Analytic investigation of the Psychopathy Checklist measures. Psychological Services, 4(1), 13-27.

Faiver, K. L. (1998). Health care management issues in corrections. Lanham, MD: American Correctional Association.

Fellner, J. (2006). A corrections quandary: Mental illness and prison rules. Harvard Civil Rights-Civil Liberties Law Review, $41,391-412$.

Fields, G. (2006, May 3). No way out: Trapped by rules the mentally ill languish in prison. Wall Street Journal, p. A1. Retrieved April 9, 2008, from http://online.wsj.com/article/SB114662497280042311.html?mod=hps_us_pageone

Florida Department of Corrections. (n.d.). Increase in number of inmates suffering from mental disorders. Retrieved April 9 , 2008, from http://www.dc.state.fl.us/pub/annual/0506/stats/ip_mental.html

Gordon, H. (2002). Suicide in secure psychiatric facilities. Advances in Psychiatric Treatment, 8, 408-417.

Gottfredson, D. M., \& Gottfredson, S. D. (1988). Stakes and risks in the prediction of violent behavior. Violence and Victims, $3(4), 247-262$.

Heikes, J. (2000). The public mental health system in Texas and its relation to criminal justice. Criminal Justice Policy Council Report. Retrieved April 9, 2008, from http://web.archive.org/web/20030705154708/http://cjpc.state.tx.us/ reports/alphalist/MIOReport1_15.pdf

Human Rights Watch. (2003). Ill-equipped: US prisons and offenders with mental illness. Retrieved April 9, 2008, from http://www.hrw.org/reports/2003/usa1003/

Jeglic, E. L., Vanderhoff, H. A., Donovick, P. J. (2005). The function of self-harm behavior in a forensic population. International Journal of Offender Therapy and Comparative Criminology, 49, 131-142.

Linhorst, D. M., Knight, K., Johnston, J. S., \& Trickey, M. (2001). Situational influences on the implementation of a prisonbased therapeutic community. The Prison Journal, 81, 436-453. 
Lovell, D., Johnson, C., Jemelka, R., Harris, V., \& Allen, D. (2001). Living in prison after residential mental health treatment: A program follow-up. The Prison Journal, 81, 473-490.

Monahan, J. (1996). Violence prediction: The past twenty years and the next twenty years. Criminal Justice and Behavior, $23,107-120$.

Oregon Department of Corrections. (2004). Managing mental illness in prisons task force: Findings and recommendations. Retrieved April 9, 2008, from http://www.oregon.gov/DOC/docs/managing_mental_illness_in_prison.doc

Parker, G. (2006). Mental illness in jails \& prisons: An overview for correctional staff. Retrieved April 9, 2008, from http://www.in.gov/indcorrection/news/030106suicidesummitjailsprisons.ppt

Peat, B. J., \& Winfree, L. T., Jr. (1992). Reducing the intra-institutional effects of "prisonization": A study of a therapeutic community for drug using inmates. Criminal Justice and Behavior, 19, 206-225.

Public Broadcasting Service. (n.d.). Frontline. Retrieved April 9, 2008, from http://www.pbs.org/wgbh/pages/frontline/ shows/crime/jailed/

Rabasca, L. (1999, September 8). High marks for psychologists who prescribe. APA Monitor Online, 30(8). Retrieved April 9, 2008, from http://www.apa.org/monitor/sep99/pr1.html

Saum, C. A., O’Connell, D. J., Martin, S. S., Hiller, M. L., Bacon, G. A., \& Simpson, D. D. (2007). Tempest in a TC: Changing treatment providers for in-prison therapeutic communities. Criminal Justice and Behavior, 34, 1168-1178.

Smiley-McDonald, H. M., \& Leukefeld, C. G. (2005). Incarcerated clients' perceptions of therapeutic change in substance abuse treatment: A 4-year case study. International Journal of Offender Therapy and Comparative Criminology, 49, 574-589.

Smith, P. S. (2006). The effects of solitary confinement on prison inmates: A brief history and review of the literature. In M. Tonry (Ed.), Crime and Justice: A review of research (pp. 441-528). Chicago: University of Chicago Press.

Taxman, F. S., \& Bouffard, J. A. (2002). Assessing therapeutic integrity in modified therapeutic communities for drug involved offenders. The Prison Journal, 82, 189-212.

Taxman, F. S., Cropsey, K. L., Young, D. W., \& Wexler, H. (2007). Screening, assessment, and referral practices in adult correctional settings: A national perspective. Criminal Justice and Behavior, 34, 1216-1234.

Thorburn, K. M. (1995). Health care in correctional facilities. Western Journal of Medicine, 163, 560-564.

Toch, H. (1992). Living in prison: The ecology of survival. Washington, DC: American Psychological Association.

Toch, H. (1998). Psychopathy or antisocial personality in forensic settings. In T. Millon, E. Simonsen, M. Birket-Smith, \& R. Davis (Eds.), Psychopathy: Antisocial, criminal and violent behavior (pp. 144-158). New York: Guilford.

Toch, H. (2007). Prevalence estimates; The numbers game. Correctional Mental Health Report, 8(5), 67-68.

Toch, H., \& Adams, K. (1986). Pathology and disruptiveness among prison inmates. Journal of Research in Crime \& Delinquency, 23(1), 7-21.

Treatment Advocacy Center. (2007). Criminalization of individual with severe psychiatric disorders. Retrieved April 9, 2008, from http://www.treatmentadvocacycenter.org/GeneralResources/Fact3.htm

U.S. Bureau of Justice Statistics. (2004). Data collection for the Prison Rape Elimination Act of 2003. Retrieved April 9, 2008, from http://www.ojp.usdoj.gov/bjs/pub/pdf/dcprea03.pdf

Vien, A., \& Beech, A. (2006). Psychopathy theory, measurement and treatment. Trauma, Violence \& Abuse, 7(3), $155-174$.

Walters, G. D., Duncan, S. A., \& Perez, K.-M. (2007). The latent structure of psychopathy: A taxometric investigation of the Psychopathy Checklist-Revised in a heterogeneous sample of male prison inmates. Assessment, 14(3), $270-278$.

Wormith, J., Althouse, R., Simpson, M., Reitzel, L., Fagan, T., \& Morgan, R. (2007). The rehabilitation and integration of offenders: The current landscape and some future directions for correctional psychology. Criminal Justice and Behavior, $34,879-892$.

Young, D. (2003). Co-occurring disorders among jail inmates: Bridging the treatment gap. Journal of Social Work Practice in the Addictions, 3, 63-85.

Zielbauer, P. V. (2003, October 23). Report says many inmates in isolation are mentally ill. New York Times. Retrieved April 9, 2008, from http://query.nytimes.com/gst/fullpage.html?res=950CEFDF1631F931A15753C1A9659C8B63\&sec=\& spon=\&pagewanted=print

Kenneth Adams is professor of public affairs and criminal justice in the College of Health and Public Affairs at the University of Central Florida. His areas of research expertise include prison violence, mentally ill offenders, police-community relations, institutional corrections, and evaluation of crime-control strategies, such as gun control and juvenile curfews. He has authored three books with Hans Toch: Coping: Maladaptation in Prison, The Disturbed Violent Offender, and Acting Out: Maladaptive Behavior in Prison.

Joseph Ferrandino is a doctoral student in public affairs at the University of Central Florida with research interests in criminal justice. 